\title{
Nutritional control of amino acid supply to the mammary gland during lactation in the pig
}

\author{
BY NATHALIE L. TROTTIER
}

Michigan State University, Department of Animal Science, East Lansing, Michigan 48824, USA

Much of the progress in understanding the physiology of lactation and the control of nutrient supply to the mammary gland has been achieved in the dairy cow. This is partly due to the combined importance of efficient milk production and its use as a major dietary component for man. Another reason is the relative ease of using the bovine model compared with the pig with regard to handling and milking. The availability of equipment that permits accurate, easy and direct measurement of total milk output in the cow certainly facilitates lactational metabolism studies in that species. Unfortunately, it is still difficult to accurately estimate milk output in the sow. Consequently, there is a dearth of information relating physiological and metabolic mechanisms to lactational performance as a basis for advancing the study of sow nutrition. It is increasingly apparent that refinements in nutritional strategies are not keeping pace with production improvements made by geneticists.

Free amino acids in blood constitute the major precursors of milk proteins, whether provided from the dietary or body protein pool, although the mechanism of delivery of these amino acids to the milk-protein synthetic machinery remains a puzzling and challenging question. Recent advances in amino acid nutrition of the lactating sow suggest that an optimum dietary ratio of the essential amino acid valine relative to lysine maximizes milk production in sows nursing large litters (Pettigrew, 1993; Richert et al. 1996). While the availability of these amino acids in the blood to the mammary system is critical for optimizing milk production, factors yet to be studied, such as blood flow and regulation of amino acid transporter systems across mammary cells, may also influence the rate of uptake. The present paper will discuss factors involved in protein metabolism as they pertain to amino acid nutrition, and a new approach to dietary control of amino acid supply for milk synthesis. It is suggested that a better understanding of whole-body protein metabolism and the control of amino acid availability to, and utilization by, the mammary gland would provide an improved basis for estimation of amino acid requirements of the lactating sow.

\section{PROTEIN AND AMINO ACID METABOLISM DURING LACTATION}

\section{Plasma amino acid dynamics}

Little importance has been given to protein degradation and its importance in sustaining milk synthesis in the sow. Amino acid metabolism and inter-organ exchange dynamics are virtually unknown in the lactating sow and there is little information relating to the concentrations of circulating amino acids during lactation. Lactation causes a substantial increase in the rate of amino acid uptake from the blood by the mammary gland to support milk synthesis (Spincer et al. 1969). Consequently, total plasma $\alpha-\mathrm{NH}_{2}-\mathrm{N}$ concentrations decrease with day of lactation (Weldon et al. 1994) and this is particularly significant for the branched-chain amino acids and alanine (Tokach et al. 1992; Trottier \& Easter, 1995). With advancing lactation, glutamine concentrations rise steadily (Trottier \& Easter, 1995) along with urea-N (Tokach et al. 1992; Hultén et al. 1993; Rojkittikhum et al. 1993), 
possibly reflecting a net release from muscle tissues and a concurrent increase in protein degradation rate respectively. This is supported by a recent study showing that the myofibrillar-protein degradation rate, as measured through $3-\left[{ }^{2} \mathrm{H}_{3}\right]$ methylhistidine kinetics, increases from approximately 2.6 to $3.1 \%$ during the first and third week of lactation respectively (Trottier, 1995). Body composition at parturition, as influenced by gestation feeding levels, also affects the dynamics of protein degradation during lactation, where myofibrillar-protein breakdown rates vary between 3.3 and $3.0 \%$ in fat sows compared with lean sows respectively. Although the hormonal control of protein metabolism is essentially unknown, we have some evidence to suggest that the dynamics of protein metabolism vary with the stage of lactation, and body compositional changes may be influenced by insulin and glucagon. However, we can only speculate on the role of insulin and/or glucagon in the control of dietary amino acid delivery to the mammary system.

\section{The role of insulin and glucagon}

While insulin promotes the uptake of amino acids, in particular the branched-chain amino acids, by peripheral tissues, it has no effect on the mammary gland. Several studies have shown that the uptake of amino acids, glucose, $\beta$-hydroxybutyrate and triacylglycerols is independent of insulin in the bovine mammary gland (Laarveld et al. 1985; Brockman \& Laarveld, 1986). The role of insulin during lactation, therefore, is unclear. Advancement of lactation in the sow is characterized by an increase in milk production capacity coupled with a decrease in circulating insulin concentrations (Trottier, 1995). Insulin concentration has been shown to be negatively correlated with sow lean tissue loss and litter-weight gain (White et al. 1984; Tokach et al. 1992). This was demonstrated previously by Reynolds \& Rook (1977) who found that insulin concentration was inversely proportional to milk yield and lactose content. Administration of insulin decreases milk production in the dairy cow (Kronfeld et al. 1963), the ewe (Leenanuruksa et al. 1988) and the sow (Goldobin, 1976). The decrease in plasma insulin concentration with advancing lactation may be the result of a combination of factors, such as: (1) lower blood glucose, as observed in the lactating sow, (2) decreased $\beta$-cell mass (Marynissen et al. 1983), (3) decreased glycaemic stimulus to the pancreas (Madon et al. 1990), (4) increased removal of the hormone by the mammary tissue (Jones et al. 1984), as observed in the lactating rat. This latter factor suggests a role for insulin in mammary tissue.

A role for insulin in mammary gland function may be substantiated by the presence of specific receptors for insulin in the mouse, rat and bovine mammary tissue (Oscar et al. 1986). This has yet to be studied, however, in the porcine mammary gland. Alternatively, since insulin has been shown to up-regulate prolactin receptors in mammary tissue, the presence of insulin receptors may be specific for this function only. Interestingly, Rojkittikhun et al. (1993) have shown that heavier sows losing more weight tend to have higher plasma prolactin concentrations. It is also possible that high concentrations of insulin may down-regulate its own receptor in mammary tissue. In the rat, insulin receptor numbers on adipocytes remain unchanged (Flint et al. 1979). In addition, no difference in insulin-binding activity on adipocytes, as measured by tyrosine kinase (EC 2.7.1.112) activity, was observed between lactating and non-lactating rats (Burnol et al. 1990). Therefore, since receptor number and binding activity in peripheral tissues remain unchanged during lactation and circulating insulin concentrations decrease, this may allow a shift of nutrients towards mammary tissues rather than peripheral tissues. In sheep, the ability of adipose tissue to respond to insulin decreases during lactation, as shown by a decreased utilization of glucose and acetate in response to an insulin surge (Vernon \& 
Taylor, 1988). Similarly, lean tissue response to insulin, as measured by arterio-venous (A-V) difference of glucose across the hindlimb after an insulin infusion, appears to be lower in the lactating rat than in the non-lactating rat (Vemon, 1989).

Regression analysis by Pettigrew et al. (1993) showed that insulin concentration was related to milk protein $(r 0.42)$, fat $(r 0.39)$ and lactose $(r 0.36)$ in the sow, indicating that insulin may account for a significant proportion of the plasma substrate uptake by the mammary gland during milk production. High circulating glucagon, coupled with decreased circulating insulin concentrations stimulates glycogenolysis and gluconeogenesis. In contrast to the increase in high-affinity insulin receptor numbers (Oscar et al. 1986), mammary tissue in the rat lacks glucagon receptors (Robson et al. 1984). This is of great significance in keeping the mammary gland in an 'anabolic status'. Both plasma glucagon and insulin concentrations are elevated during the early post-partum period, and their concentrations may be affected by the body composition of the sow (Trottier, 1995). While insulin decreases with advancing lactation, glucagon concentration decreases in lean sows and increases in fat sows, although the molar ratio, insulin: glucagon decreases in both fat and lean sows, thus contributing to the increase in body protein breakdown. Lower insulin concentrations are also associated with high cortisol concentrations (Baidoo et al. 1992), contributing further to protein degradation rate.

\section{AMINO ACID DELIVERY TO THE MAMMARY GLAND}

\section{Blood flow and milk production}

While amino acids are supplied to the arterial circulation through either dietary intake or body protein mobilization, the efficiency of delivery to the mammary system is dependent on blood flow and the efficiency of amino acid carrier systems across the mammary cellular membranes. As lactation advances, the A-V difference for lysine remains constant, with an increase in extraction rate and a parallel linear decrease in arterial lysine concentration (Trottier et al. 1997). The increased extraction rate is indicative of increased blood flow and/or an increased rate of uptake at the mammary cellular level. The effect of nutrition or genetics on blood flow and receptor regulation is unknown.

For many years it has been known (Linzell, 1960) that there is a close correlation between udder blood flow and milk yield in the goat in which blood flow rises at parturition and increases steadily as lactation advances. The relationship between direct blood flow and milk yield in the lactating sow has not been studied. In using an indirect approach, the Fick method for estimating blood flow in the lactating sow, Trottier et al. (1997) found that blood flow was correlated with milk yield. In turn, milk yield was positively correlated with A-V differences of all essential amino acids. This supports the earlier suggestion by Pettigrew et al. (1993) that total nutrient supply to the mammary gland (nutrients concentration $\times$ blood flow), rather than only metabolite concentrations, would be more closely related to milk yield and lactational performance, since milk protein, fat and lactose are poorly related to their concentrations in plasma.

\section{Blood flow and methodological difficulties in the lactating sow}

Accurate measurement of blood flow to the mammary gland would contribute immensely to the understanding of lactational physiology and nutritional control of amino acid supply for milk synthesis in the pig. The biggest impediment to direct blood flow measurement in the porcine mammary system is the anatomical and vascular complexity. While the mammary circulatory system of the ruminant is localized in the inguinal region, the pig 
circulatory system is multiple, extending from the xiphisternum to the groin (Linzell, 1974). The porcine mammary system can be divided into three regions, i.e. inguinal, abdominal and thoracic (Bourdelle \& Bressou, 1964). In the sow, the external pudendal artery runs downward and descends through the inguinal canal. At this point, in contrast to the bovine mammary system, it divides into three main branches, i.e. the lateral, middle cranial and medial cranial of the external pudendal artery. These branches are also called lateral, middle cranial and medial cranial branches of the caudal superficial epigastric artery. These branches extend from the inguinal to the mid-abdominal region, carrying blood for up to four pairs of posterior mammary glands rather than the whole mammary system. In the cow, the external pudendal artery becomes the main mammary artery, running from the posterior to anterior gland regions, hence supplying nutrients to the whole mammary system. In contrast to the sow, the pudendal artery branches off into the lateral basal and the medial basal arteries just before leaving the anterior mammary glands and entering the abdominal region, and the lateral basal branch of the main mammary (pudendal) artery anastomoses with deep branches of the cranial epigastric artery. In the sow, despite multiple dissections of the vascular system, it is still unclear as to how, where and which of the branches of the pudendal artery anastomose with the cranial epigastric artery.

The venous drainage is also puzzling and does not offer an alternative approach to direct measurement of blood flow, since anatomical evaluation of the circulatory system suggests that blood leaves the mammary glands using two different pathways (Trottier $e t$ al. 1995). The anterior glands are drained through two large longitudinal mammary veins, also referred to as the subcutaneous abdominal veins. These veins run parallel on each side of the line of mammary glands. Dissection of the mammary system showed that they are readily identifiable, running along in the plica lateralis (Trottier et al. 1995). These vessels drain into the internal thoracic vein, while some other branches drain into the external thoracic vein. It has been suggested that blood leaves the posterior mammary glands by war of the same subcutaneous abdominal vein found in the anterior region and drains into the external pudic vein (Bourdelle \& Bressou, 1964; Linzell, 1974), thus implying two different regulatory flow systems. In ruminants, because the mammary glands are inguinal, the vasculature is simplified and only the caudal superficial epigastric vessels drain the mammary tissue. Virgin female and male ruminants resemble the lactating sow, since blood drains forwards into the cranial vein in the anterior and abdominal region of the abdomen and backward (cranial to caudal) into the caudal vein in the inguinal region. During mammary gland development and lactatogenesis, the posterior vein enlarges progressively upon the increase in flow of blood entering the inguinal region, and consequently valves become incompetent. As a result, the blood flows entirely from the inguinal region toward the cranial superficial epigastric vein. This facilitates both measurement of nutrient output and flow rate in both the lactating goat and the cow. This developmental process does not seem to occur in the pig.

\section{SUPPLY OF AMINO ACIDS TO THE MAMMARY SYSTEM: DIETARY CONSIDERATION}

\section{Practical dietary approach}

Pettigrew (1993) has described extensively a factorial approach to the estimation of dietary requirements based on litter growth rate and the pattern of amino acids relative to lysine contained in milk, thus aiming at an 'ideal' protein estimation. Current production trends imposed on lactating sows and the resulting lactation response to feeding crystalline amino acids indicate that key amino acids other than lysine may be critically needed during 
lactation. In a recent cooperative experiment, Knabe et al. (1996) suggested that the addition of crystalline lysine alone, more than $7.5 \mathrm{~g} \mathrm{lysine} / \mathrm{kg}$, to a $135 \mathrm{~g}$ crude protein $(\mathrm{N} \times 6.25) / \mathrm{kg}$ diet, would not improve litter performance, possibly due to other limiting amino acids. This strengthens the importance of formulating lactating-sow diets based on an ideal profile. In a recent study by Coma et al. (1996), adult sows nursing ten-pig litters with an average total growth of $2.2 \mathrm{~kg} / \mathrm{d}$ required $55 \mathrm{~g}$ lysine/d to minimize plasma urea-N (PUN) concentrations, with sows consuming $66 \mathrm{~g}$ valine/d. The method used by Coma $e t$ al. (1996) assumes that $\mathrm{N}$ balance is maximized and body protein catabolism minimized when PUN reaches a constant minimum concentration. They estimated that $55 \mathrm{~g}$ lysine was required daily to minimize protein catabolism and maximize lactational performance. This value is extremely close to the modelling estimate by Pettigrew (1993). In another recent study, incremental amounts of dietary valine resulting in valine : lysine values from 83.3 to $127.8(7.5-11.5 \mathrm{~g}$ valine $/ \mathrm{kg})$ resulted in a positive linear litter-growth-rate response (Richert et al. 1996). This may not indicate that valine is a limiting amino acid since parallel increases in PUN were observed, suggesting that valine was being oxidized rather than incorporated into proteins. Increased performance response to increased valine may thus be related to some property of valine itself other than as a 'limiting' amino acid.

Higher dietary ratios of amino acids relative to lysine are now proposed, as opposed to using the values initially observed in milk. This is particularly the case with valine and to some extent leucine. The role of the mammary gland in terms of physiological and nutritional demand per se has not been previously considered. It is becoming more apparent that an understanding of this missing link is essential for devising a biological basis for dietary recommendations and in building mathematical models to predict amino acid requirements.

\section{Effect of nutrition on mammary amino acid uptake}

Amino acids are made available to the mammary gland via the arterial supply, mostly as free entities in plasma and erythrocytes. However, evidence from the goat suggests that peptide-bound amino acids may contribute to the pool of amino acids found in milk casein (Backwell et al. 1994). In addition, L. Hoffmann, N. L. Trottier, B. J. Bequette, T. T. Nielsen and R. A. Easter (unpublished results) have demonstrated that plasma free leucine uptake by the mammary gland is insufficient to account for all leucine present in milk casein.

The relationship between A-V difference of essential amino acids across the mammary gland and arterial concentration of these amino acids (Fig. 1) demonstrates that the relative amino acid $\mathrm{A}-\mathrm{V}$ differences are a function of their relative concentration in the arterial plasma. For example, A-V difference for leucine is the highest, as reflected by leucine concentration in the arterial plasma. The question of whether a similar relationship would be obtained through dietary alteration of each individual amino acid remains. We have found that the A-V difference for lysine increases quadratically with an increase in arterial lysine concentration (Fig. 2). The inflexion point may correspond with the requirement necessary for milk protein synthesis, and a further increase in arterial lysine concentration, hence from the diet, does not result in a further increase in mammary uptake. The region of linear increase would correspond with the limiting lysine status. On the other hand, no relationships between arterial concentration and $\mathrm{A}-\mathrm{V}$ difference were observed for the other essential amino acids such as leucine (Fig. 3) and valine (Fig. 4), suggesting that these amino acids are not readily limiting in milk synthesis and that mammary gland uptake rapidly reaches saturation. 


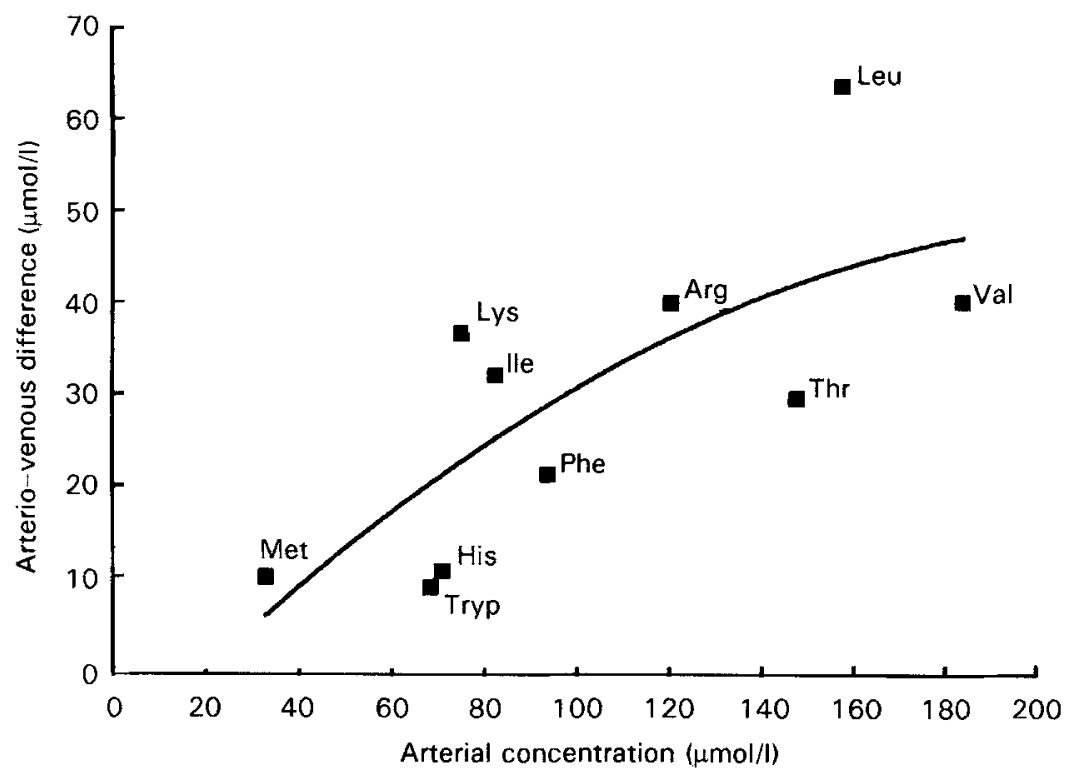

Fig. 1. Relationship between amino acid arterial concentration and arterio-venous difference $\left(r^{2} 0.57\right)$. Data are overall average lactation arterial concentration and arterio-venous difference for each essential amino acid. (From Trottier $e t$ al. 1997.)

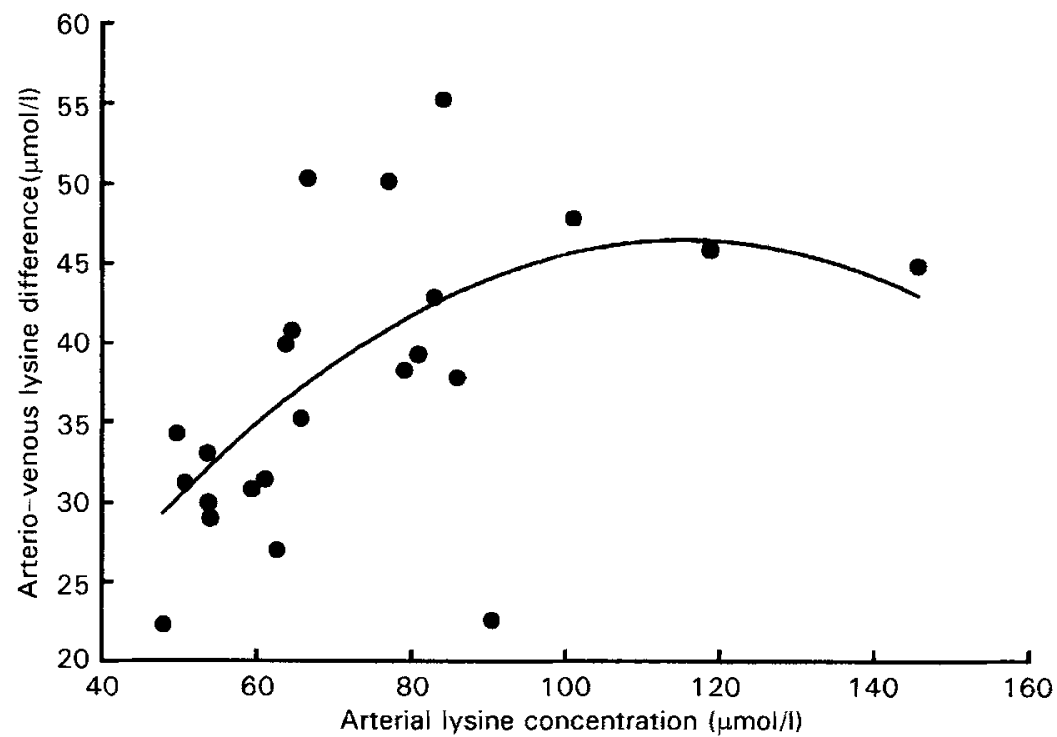

Fig. 2. Relationship between lysine arterial concentration and arterio-venous lysine difference $\left(r^{2} 0-32\right)$. Data from an individual sow sampled at day 11,14, 17 and 20 of lactation. Arterio-venous lysine difference represents arterial concentration of lysine minus mammary venous concentration of lysine. (From Trottier, 1995.) 


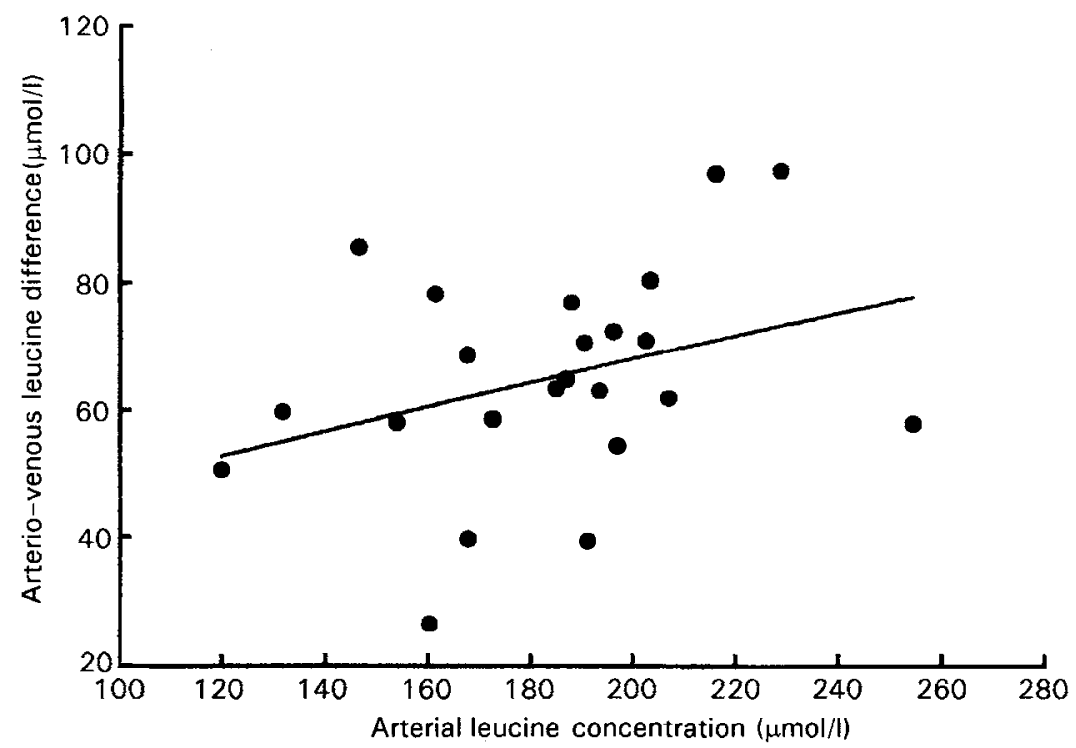

Fig. 3. Relationship between leucine arterial concentration and arterio-venous leucine difference $\left(r^{2} 0 \cdot 10\right)$. Data from an individual sow sampled at day $11,14,17$ and 20 of lactation. Arterio-venous difference represents arterial concentration of leucine minus mammary venous concentration of leucine. (From Trottier, 1995.)

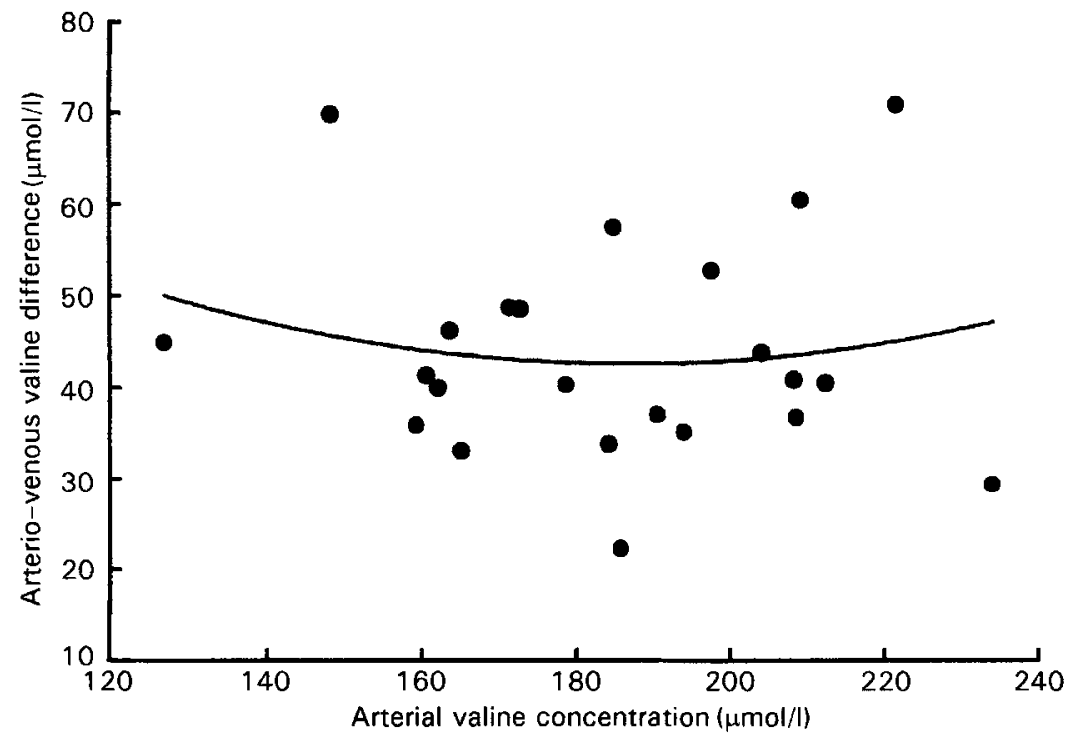

Fig. 4. Relationship between valine arterial concentration and arterio-venous valine difference $\left(r^{2} 0.02\right)$. Data from an individual sow sampled at day $11,14,17$ and 20 of lactation. Arterio-venous difference represents arterial concentration of valine minus mammary venous concentration of valine. (From Trottier, 1995.) 
Table 1. Amino acid (AA) pattern relative to lysine in sow milk and in mammary uptake pool

\begin{tabular}{lccc}
\hline \hline & & \multicolumn{2}{c}{ Mammary AA uptake : lysine } \\
\cline { 3 - 4 } AA & Milk AA : lysine & Trottier et al. (1997) & Nielsen et al. (1997) \\
\hline Arginine & 0.66 & 1.25 & 1.09 \\
Histidine & 0.40 & 0.30 & 0.28 \\
Isoleucine & 0.55 & 0.76 & 0.79 \\
Leucine & 1.15 & 1.50 & 1.48 \\
Lysine & 1.00 & 1.00 & 1.00 \\
Methionine & 0.26 & 0.28 & 0.26 \\
Phenylalanine & 0.55 & 0.65 & 0.61 \\
Threonine & 0.58 & 0.68 & 0.64 \\
Valine & 0.73 & 0.88 & 0.89 \\
\hline \hline
\end{tabular}

Table 1 shows that amino acids are taken up in very similar proportion relative to lysine, whether dietary lysine is $6.3 \mathrm{~g} / \mathrm{kg}$ (Trottier et al. 1997) or $9.0 \mathrm{~g} / \mathrm{kg}$ (Nielsen et al. 1997), with the exception of arginine. Higher lysine levels may decrease mammary arginine uptake through an increase in mammary arginase $(E C$ 3.5.3.1) activity, although the presence of an arginase enzyme in porcine mammary tissue has never been investigated. The discrepancy observed between the amino acid pattern in milk and amino acid uptake pattern by mammary tissue relative to lysine gives rise to new thoughts on the estimation of dietary amino acid requirements. The mammary amino acid uptake pattern represents a combination of both independent mammary metabolism needs or functions and milk amino acid output. Thus, it is likely that the required amino acid profile for lactating sow would better resemble the amino acid pattern of mammary uptake rather than the amino acid pattern of milk.

\section{Mammary amino acid retention}

Amino acid uptake exceeds quantitative excretion in milk, especially for branched-chain amino acids and arginine (Trottier et al. 1997). Of the total $188.5 \mathrm{~g}$ essential amino acids taken up by the sow mammary gland daily, $49 \mathrm{~g}$ are retained, accounting for about $25 \%$ of the total uptake (Trottier et al. 1997). This significant 'mammary retention' may indicate specific requirements at the mammary cellular level per se, although excess leucine uptake in the bovine mammary gland has been suggested to be the result of a counter-current uptake mechanism between the erythrocytes and the mammary cells (Hanigan et al. 1991). Amino acids that 'appear' to be taken up in excess of their output in milk may be 'biologically required' by the mammary gland. This assumption would imply that the mammary gland is not in a steady-state with regard to protein synthesis.

Retention may be divided into two distinct components: maintenance and metabolic functions. For example, mammary amino acid maintenance requirement may be estimated from regression of mammary amino acid uptake $v$. daily milk production (Fig. 5) by fitting the ordinate to zero. The difference between retention and maintenance values may indicate the potential use of amino acids for other metabolic functions (Table 2). It has been suggested that the accumulation of amino acids by the mammary gland in the cow and goat may stimulate the synthesis of non-essential amino acids, functional and structural proteins, and provide energy available for lactose and fatty acid synthesis (Spires et al. 


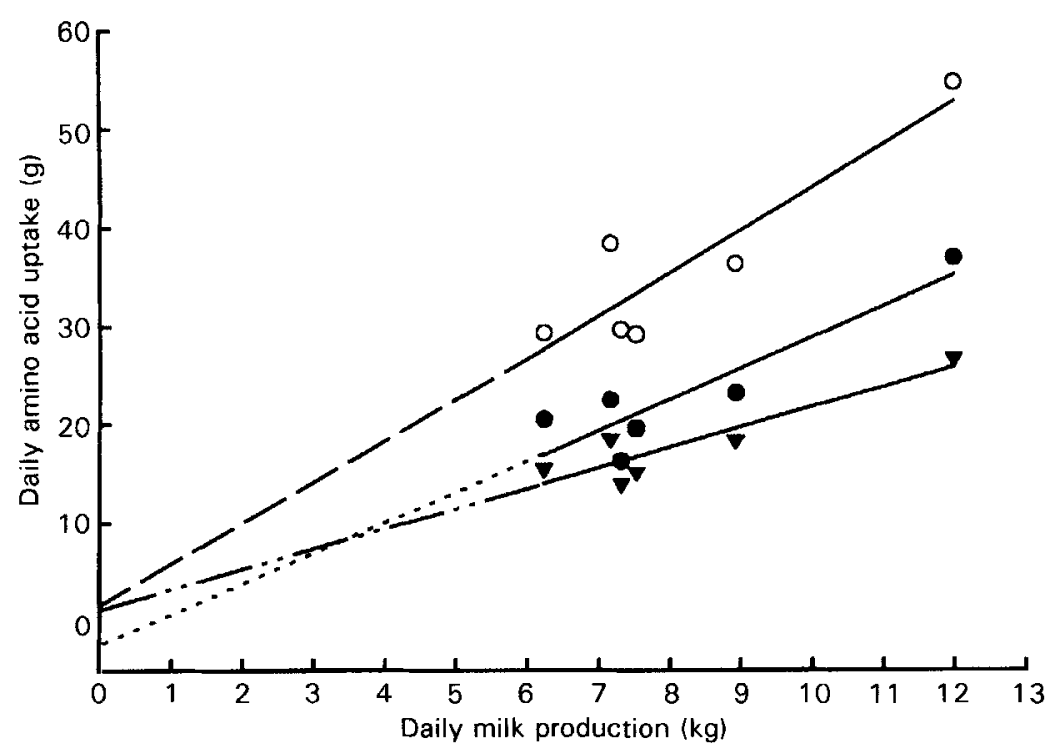

Fig. 5. Relationship between daily milk production and daily uptake of leucine $(0)$, lysine $(\boldsymbol{O})$ and isoleucine $(\boldsymbol{\nabla})$ by the porcine mammary gland. $(--)$, Leucine; $(\cdots)$, lysine; $(-\cdots-\cdots-)$, isoleucine; each indicates extrapolation to the $y$ intercept and estimate of mammary maintenance requirement of leucine, lysine and isoleucine respectively, when daily milk production equals zero. Regression equations are: mammary leucine uptake $(\mathrm{g} / \mathrm{d})=4.41 x+0.34, r^{2} 0.83$; mammary lysine uptake $(\mathrm{g} / \mathrm{d})=3 \cdot 22 x-3 \cdot 00, r^{2} 0 \cdot 82$; mammary isoleucine uptake $(\mathrm{g} / \mathrm{d})=2 \cdot 10 x+1 \cdot 18, r^{2} 0.83$. Maintenance requirement for leucine, lysine, and isoleucine is estimated at $0.34,-3.00$, and $1.18 \mathrm{~g} / \mathrm{d}$ respectively.

1975). Isoleucine is a putative source of energy required for milk biosynthesis (Hanigan $e t$ al. 1991). Leucine metabolites such as $\alpha$-ketoisocaproate and isovalerate, and $\beta$-hydroxy- $\beta$ methyl butyrate have been shown to increase milk fat secretion when fed to sows (Nissen $e t$ al. 1994). Valine, which is a strictly glucogenic amino acid, cannot be incorporated into lipids. Because gluconeogenesis occurs predominantly in the liver and kidney tissues, and glucagon receptors are absent in mammary tissue, at least in the rat, the use of valine as a $\mathrm{C}$ source for de novo mammary glucose synthesis is unlikely. Biologically speaking, the mammary gland is an 'anabolic' organ, while gluconeogenesis occurs in a catabolic environment.

Although the fate of essential amino acids in the lactating mammary gland has stimulated much interest, the actual control of their uptake and their metabolic fate remain uncertain. Because the mammary gland is a unique entity in which active cellular

Table 2. Daily mammary retention, maintenance requirement estimates, and utilization for metabolic functions of selected amino acids

\begin{tabular}{lccc}
\hline \hline Amino acid & Retention* $(\mathrm{g} / \mathrm{d})$ & Maintenance $\dagger(\mathrm{g} / \mathrm{d})$ & Metabolic functions + \\
\hline Leucine & 10.71 & 0.34 & 10.37 \\
Lysine & 0 & -3.00 & 3.00 \\
Isoleucine & 6.24 & 1.18 & 5.06 \\
Threonine & 3.40 & 0.96 & 2.44 \\
Valine & 5.42 & 5.81 & -0.39 \\
\hline
\end{tabular}

* Data from Trottier et al. (1997).

† Obtained from regression of mammary amino acid uptake $v$. daily milk production.

¥ Obtained by difference between retention and maintenance requirement estimates. 
breakdown and remodelling occur continuously, research is needed to assess the energy costs and control of amino acid requirements associated with mammary gland maintenance during lactation.

\section{SUMMARY}

The paucity of data relating to lactation physiology of the sow has frustrated researchers in estimating nutrient needs for production and mammary maintenance functions. The nutritional control of amino acid supply for milk synthesis is influenced by factors that have yet to be measured, such as blood flow and amino acid contribution from the body protein pool. The interaction or role of hormones such as insulin, glucagon or prolactin in amino acid dynamics and inter-organ exchange during lactation in the sow, are not well understood. The discrepancy existing between milk and mammary amino acid uptake profiles relative to lysine may be indicative of mammary metabolism and possibly maintenance requirements for specific amino acids. Hence, amino acid metabolism in the mammary gland, regardless of arterial blood substrate supply, may play an important role in a factorial approach to determining requirements. Mammary amino acid uptake ratios rather than milk amino acid ratios should provide a better tool to estimate amino acid requirements relative to lysine. Although lysine has typically been limiting in maizesoyabean-meal-based diets fed to lactating sows, current production trends are bringing a new dimension to the formulation of lactating-sow diets. Other amino acids may become limiting if dietary crystalline lysine is added without concern for the whole essential amino acid profile. Formulations based on an ideal amino acid profile for the lactating sow will, therefore, become critical.

\section{REFERENCES}

Baciviell, F. R., Bequette, B. J., Wilson, D., Calder, A. G., Metcalf, J. A., Wray-Cahen, D., MacRae, J. C., Beever, D. E. \& Lobley, G. E. (1994). Utilization of dipeptides by the caprine mammary gland for milk protein synthesis. American Journal of Physiology 267, R1-R6.

Baidoo, S. K., Lythgoe, E. S. \& Kirkwood, R. N. (1992). Effect of lactation feed intake on endocrine status and metabolite levels in sows. Canadian Journal of Animal Science 72, 799-807.

Bourdelle, E. \& Bressou, C. (1964). Anatomie Régionale des Animaux Domestiques. III. Le Porc, 2nd ed. [C. J. P. Bressou, editor]. Paris: Baillière et Fils.

Brockman, R. P. \& Laarveld, B. (1986). Hormonal regulation of metabolism in ruminants. A review. Livestock Production Science 14, 313-334.

Burnol, A., Ebner, S., Kande, J. \& Girard, J. (1990). Insulin resistance of glucose metabolism in isolated brown adipocytes of lactating rats. Biochemical Journal 265, 511-517.

Coma, J., Zimmerman, D. R. \& Carrion, D. (1996). Lysine requirement of the lactating sow determined by using plasma urea nitrogen as a rapid response criterion. Journal of Animal Science 74, 1056-1062.

Flint, D. J., Sinnet-Smith, P. A., Clegg, R. A. \& Vernon, R. G. (1979). Role of insulin receptors in the change in metabolism of adipose tissue during pregnancy and lactation in the rat. Biochemical Journal 182, $421-427$.

Goldobin, M. I. (1976). The effect of hyperinsulinemia on milk secretion and composition in sows. Animal Breeding Abstracts 44, 425.

Hanigan, M. D., Calvert, C. C., DePeters, E. J., Reis, B. L. \& Baldwin, R. L. (1991). Whole blood and plasma amino acid uptakes by lactating bovine mammary glands. Joumal of Dairy Science 74, 2484-2490.

Hultén, F., Neil, M., Einarsson, S. \& Håkansson, I. (1993). Energy metabolism during late gestation and lactation in multiparous sows in relation to backfat thickness and the interval from weaning to first estrus. Acta Veterinaria Scandinavica 34, 9-20.

Jones, R. G., Ilic, V. \& Williamson, D. H. (1984). Physiological significance of altered insulin metabolism in the conscious rat during lactation. Biochemical Joumal 220, 455-460.

Knabe, D. A., Brendemuhl, J. H., Chiba, L. I. \& Dove, C. R. (1996). Supplemental lysine for sows nursing large litters. Journal of Animal Science 74, 1635-1640.

Kronfeld, D. S., Mayer, G. P., Robertson, J. M. \& Raggi, F. (1963). Depression of milk secretion during insulin administration. Journal of Dairy Science 46, 559-563. 
Laarveld, B., Chaplin, R. K. \& Brockman, R. P. (1985). Effect of insulin on the metabolism of acetate, $\beta$ hydroxybutyrate and triglycerides by the bovine mammary gland. Comparative Biochemistry and Physiology 82B, 265-267.

Leenanuruksa, D., Niumsup, P. \& McDowell, G. H. (1988). Insulin affects glucose uptake by muscle and mammary tissues of lactating ewes. Australian Journal of Biological Science 41, 453-461.

Linzell, J. L. (1960). Mammary-gland blood flow and oxygen, glucose and volatile fatty acid uptake in conscious goat. American Joumal of Physiology 153, 492-509.

Linzell, J. L. (1974). Mammary blood fiow and substrate uptake. In Lactation, A Comprehensive Treatise. vol. 1, The Mammary Gland, Development and Maintenance, p. 143 [Bruce L. Larson and Vearl R. Smith, editors]. New York and London: Academic Press.

Madon, R. I., Ensor, D. M. \& Flint, D. J. (1990). Hypoinsulinaemia in the lactating rat is caused by a decreased stimulus to the pancreas. Journal of Endocrinology 125, 81-88.

Marynissen, G., Aerts, L. \& van Asschef, F. A. (1983). The endocrine pancreas during pregnancy and lactation in the rat. Journal of Developmental Physiology 5, 373-381.

Nielsen, T. T., Trottier, N. L., Stein, H. H. \& Easter, R. A. (1997). Effect of litter size on amino acid uptake by the mammary gland in the lactating sow. Proceedings of the Third Joint European Association for Animal Production/American Society of Animal Science Workshop on Biology of Lactation in Farm Animals, Lillehammer, Norway. (In the Press).

Nissen, S., Faidley, T. D., Zimmerman, D. R., Izard, R. \& Fisher, C. T. (1994). Colostral milk fat percentage and pig performance are enhanced by feeding the leucine metabolite $\beta$-hydroxy- $\beta$-methyl butyrate to sows. Journal of Animal Science 72, 2331-2337.

Oscar, T. P., Baumrucker, C. R. \& Etherton, T. D. (1986). Insulin binding to bovine mammary membranes: comparison of microsomes versus smooth membranes. Journal of Animal Science 62, 179-186.

Pettigrew, J. E. (1993). Amino acid nutrition of gestating and lactating sows. Biokyowa Technical Reviews 5, 1-18.

Pettigrew, J. E., McNamara, J. O., Tokach, M. D., King, R. H. \& Crooker, B. A. (1993). Metabolic connections between nutrient intake and lactational performance in the sow. Livestock Production Science 35, 137-152.

Reynolds, L. \& Rook, J. A. F. (1977). Intravenous infusion of glucose and insulin in relation to milk secretion in the sow. British Journal of Nutrition 37, 45-53.

Richert, B. T., Tokash, M. D., Goodband, R. D., Nelssen, J. L., Pettigrew, J. E., Walker, R. D. \& Johnston, L. J. (1996). Valine requirement of the high producing lactating sow. Journal of Animal Science 74, 1307-1313.

Robson, N. A., Clegg, R. A. \& Zammit, V. A. (1984). Regulation of peripheral lipogenesis by glucagon. Inability of the hormone to inhibit lipogenesis in mammary acini in vitro in the presence or absence of agents which alter its effect on adipocytes. Biochemical Journal 217, 743-749.

Rojkittikhun, T., Einarsson, S., Uvnäs-Moberg, K. \& Edqvist, L. E. (1993). Body weight loss during lactation in relation to energy and protein metabolism in standard-fed primiparous sows. Journal of Veterinary Medicine 40A, 249-257.

Spincer, J., Rook, J. A. \& Toweres, K. G. (1969). The uptake of plasma constituents by the mammary gland of the sow. Biochemical Journal 111, 727-732.

Spires, H. R., Clark, J. H., Derrig, R. G. \& Davis, C. L. (1975). Milk production and nitrogen utilization in response to post-ruminal infusion of sodium caseinate in lactating cows. Joumal of Nutrition 105, 1111-1121.

Tokach, M. D., Pettigrew, J. E., Dial, G. D., Wheaton, J. E., Crooker, B. A. \& Johnston, L. J. (1992). Characterization of luteinizing hormone secretion in the primiparous sow: Relationship to blood metabolites and return-to-estrus interval. Joumal of Animal Science 70, 2195-2201.

Trottier, N. L. (1995). Protein metabolism in the lactating sow. PhD Thesis, University of Illinois.

Trottier, N. L. \& Easter, R. A. (1995). Dietary and plasma branched-chain amino acids in relation to tryptophan: Effect on voluntary feed intake and lactation metabolism in the primiparous sow. Journal of Animal Science 73, $1086-1092$

Trottier, N. L., Shipley, C. F. \& Easter, R. A. (1995). A technique for the venous cannulation of the mammary gland in the lactating sow. Journal of Animal Science 73, 1390-1395.

Trottier, N. L., Shipley, C. F. \& Easter, R. A. (1997). Plasma amino acid uptake by the mammary gland of the lactating sow. Journal of Animal Science (In the Press).

Vernon, R. G. (1989). Endocrine control of metabolic adaptation during lactation. Proceedings of the Nutrition Society 48, 23-32.

Vernon, R. G. \& Taylor, E. (1988). Insulin, dexamethasone and their interactions in the control of glucose metabolism in adipose tissue from lactating and non-lactating sheep. Biochemical Journal 256, 509-514.

Weldon, W. C., Lewis, A. J., Louis, G. F., Kovar, J. L., Giesemann, M. A. \& Miller, P. S. (1994). Postpartum hypophagia in primiparous sows: I. Effects of gestation feeding level on feed intake, feeding behavior, and plasma metabolite concentrations during lactation. Journal of Animal Science 72, 387-394.

White, C. E., Head, H. H., Bachman, K. C. \& Bazer, F. W. (1984). Yield and composition of milk and weight gain of nursing pigs from sows fed diets containing fructose or dextrose. Journal of Animal Science 59, 141150 . 